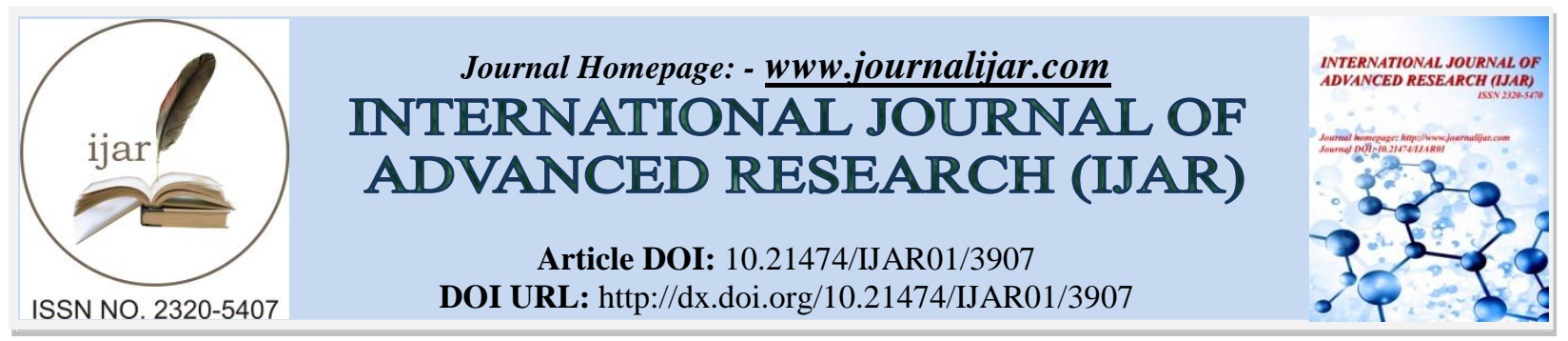

RESEARCH ARTICLE

\title{
SUCCESSFUL MANAGEMENT OF FRACTURED ANTERIOR TOOTH FRAGMENT: A CASE REPORT
}

B. G. Yogesh, Shwetha. H. K, P. V. Sreedevi, Arun. J. Kumar, Ashwini. B and Srinivas. M.

\section{Manuscript Info}

Manuscript History

Received: 19 February 2017

Final Accepted: 20 March 2017

Published: April 2017

Key words:-

Reattachment, Flowable composite,

Subgingival, Fracture

\begin{abstract}
Esthetic rehabilitation of crown fractured anterior teeth is one of the greatest challenges to the dental specialist in concern of long term biological function. Complicated crown fractures involving the enamel, dentin and pulp constitute a major share of all dental injuries and are most common in maxillary central incisors. A fractured anterior tooth requires immediate clinical attention and if untreated, can cause damage to dentition and even have a psychological impact on the patient. This case report represents the management of a fractured left maxillary lateral incisor of 21 year old male patient were his own fractured tooth fragments restored by reattachment technique. The clinical examination revealed complicated crown fracture extending subgingivally with pulp exposure. The treatment included root canal treatment and glass fiber post for reinforcement. The tooth fragment was luted with light activated flowable composite rein and showed good esthetics.
\end{abstract}

Copy Right, IJAR, 2017,. All rights reserved.

\section{Introduction:-}

Coronal fractures of the anterior teeth are a common form of dental trauma that mainly affects children and adolescents ${ }^{7,10}$. The most affected teeth are maxillary incisors due to their anterior position and protrusion ${ }^{1}$. The common etiological factor of crown or crown root fracture in the permanent dentition is injury caused by fall, contact sports, automobile accident and foreign body striking the teeth. Crown fractures have been documented to account for up to $92 \%$ of all traumatic injuries to the permanent dentition. Esthetic rehabilitation of crown fracture of the maxillary anterior teeth is one of the greatest challenges to the dental specialist ${ }^{2}$.

Reattaching the fractured tooth fragment to the tooth remnant enhances the durability of the restoration, since the fragment wears at the same rate as that of the other teeth. Also, the natural enamel translucency and surface finish of the fragment provides the tooth with its original esthetics and it is economical ${ }^{8}$. This paper reports a case of complicated coronal fracture successfully managed by tooth fragments reattachment.

\section{Case Report:-}

A 21 year old male reported to the Department of Conservative dentistry and Endodontics, Farooqia dental college, Mysore(India), with a chief complaint presenting crown fracture in left maxillary lateral incisors due to fall from sports 3 hrs back. After general, medical, dental histories were reviewed, clinical and radiographic examinations were conducted [ FIG 1]. On clinical examination, fracture line extended from labial to lingual in apical direction. The fragment was still attached by a soft tissue junction at the palatal aspect [ FIG 2]. Radiographically it revealed 
fractured tooth with a loss of tooth structure extending to the middle to cervical $1 / 3^{\text {rd }}$ with an exposure of the root canals [FIG 3].

The patient was explained about the treatment options as post and core and crown or extraction of the teeth followed fixed partial denture or implants. Patient insisted for reattachment of the same tooth. The advantages and disadvantages of the all feasible treatment were explained to the patient. The patients consent was taken prior to initiation of the treatment.

Local anesthesia was administered and the fracture fragment was removed and stored in saline. Root canal treatment was initiated and completed in a single sitting. As crown fracture was extended subgingivally $2-3 \mathrm{~mm}$ rubber dam isolation was not performed. The post space was prepared using peeso reamers (Mani, prime Dental product) with preserving a $5 \mathrm{~mm}$ of apical seal. A suitable fiber post was selected and checked for proper adaptation [FIG 6]. Radiographic evaluation of the fiber post [FIG 5] was performed for satisfactory adaptation of post. Palatally flap was raised to gain access [FIG 6]. The self cured resin cement (Rely $\mathrm{X}^{\mathrm{TM}} \mathrm{U} 100$ ) was applied to the inner potion of the canals with the help of a lentulo spiral and lightly applied to the surface of the posts, which then inserted into the canals under constant digital pressure until the end of the cement polymerizes under manufacturer's instructions [FIG 7].

Later the core build up was done using flowable composite restorative material (3M ESPE) [FIG 8]. The margins were polished with composite finishing kit. Occlusion was checked and post operative instructions were given [FIG 9]. The patient was kept on periodic review and it was observed that both endodontic and restorative treatments remained clinically acceptable through each visit.

\section{Pictures:-}

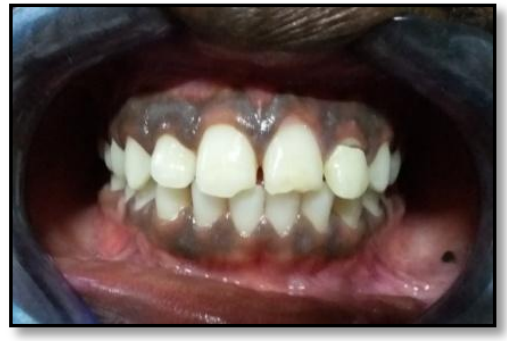

FIG.1

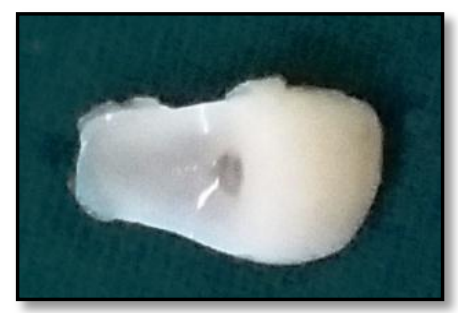

FIG.4

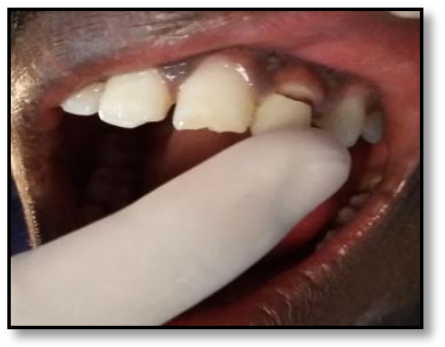

FIG.2

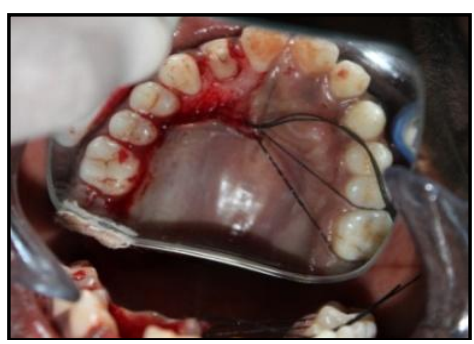

FIG.5

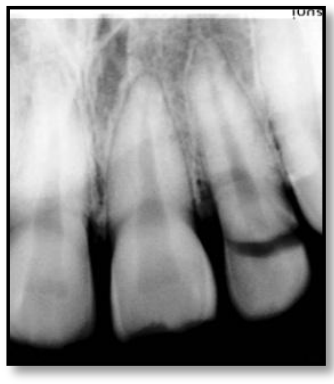

FIG.3

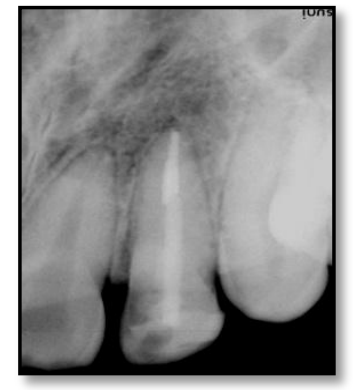

FIG.6 


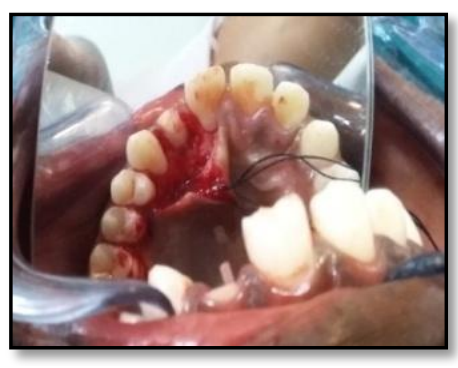

FIG.7
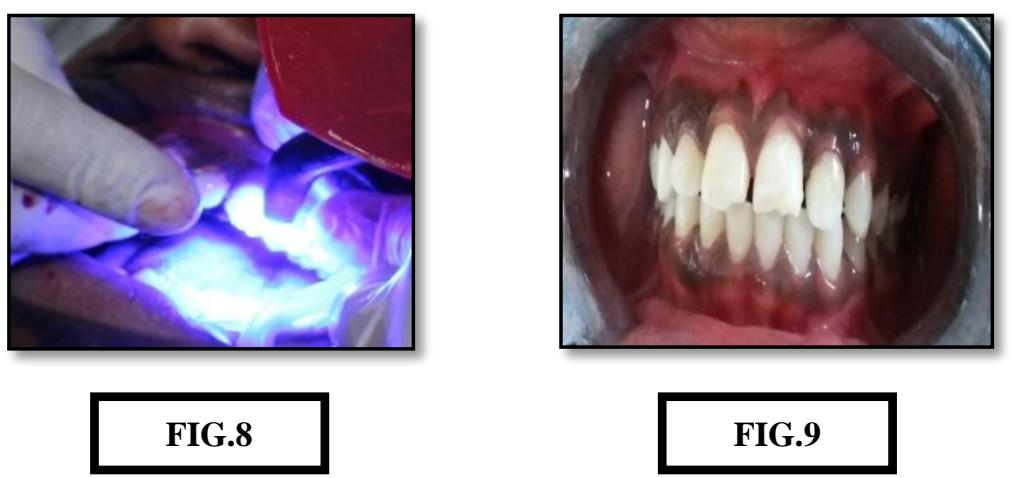

\section{Discussion:-}

Management of crown and crown root fractures pose a challenge to the clinical as several factors may play a role in their management. These factors include:

- The extent of the fracture ( complicated or uncomplicated, violation of biological width, alveolar bone fracture, concomitant luxation injury)

- Restorability of the fractured tooth and fracture pattern (subgingival extension of the fracture line and/ or associated root fracture)

- Availability of the fractured fragment and its condition for use( fit of the fragments to the remaining tooth surface)

- Secondary soft tissue injuries

- Occlusion, esthetics and finance ${ }^{6}$.

The treatment options for anterior tooth trauma can range from direct resin based composite restoration, tooth fragment bonding, ceramic veneer, root canal treatment and tooth fragment rebonding, root canal treatment and crown with or without post and core and extraction followed by replacement ${ }^{6}$.

However, ideal coronal reconstruction of an endodontically treated tooth is still a challenge for restorative dentistry. Better intracanal retention and stability of coronal restoration can be achieved using posts made from different materials such as fiber glass, carbon fiber, metal and ceramic.

Development of the adhesive materials creates new perspective in reconstruction of fractured teeth, it is now possible to achieve excellent results with reattachment of dislocated tooth fragment provided that the biological factors, materials and techniques are logically assessed and managed ${ }^{\mathbf{1 2}}$. Reattachment should be the first choice of treatment includes regaining colour and size of the original tooth, being worn away in similar proportion to adjacent tooth and giving positive psychological response to the patient and is also economical ${ }^{1}$. The fractured fragment needs to be splinted with adjacent teeth if delay is expected in completing endodontic treatment due to possible damage to the periodontium?.

In case of complicated fractures when endodontic therapy is required, the space provided by the pulp chamber can be used as an inner reinforcement thus avoiding further preparation of fractured tooth. The use of post increases retention and distributes the stress along the root, with the help of the glass fiber post the fractured crown can be permanently bonded to the root. Connecting the fiber post with the resin cement increases the retention of segment and provides a monoblock effect.

In this case reattachment was possible because the fractured fragment was intact and we could achieve a good approximation as the crown and post were inserted as a single unit and thorough curing of the composite was achieved as it was cured extra orally ${ }^{1}$.

Clinically trials and long term follow up have reported that reattachment using modern dentin bonding agents or adhesive luting system may achieve functional and esthetic success ${ }^{\mathbf{7 1 2}}$. 
Sapna CM, Priya R etal ${ }^{3}$ reported successful management of three cases of reattachment of fractured tooth fragment with fiber post.

Shivakumar A et $\mathrm{al}^{1}$ reported a similar case with a complicated crown fracture which was attached onto a glass fiber post ( intra canal anchorage) which then repositioned using resin luting cement.

Trope et $\mathrm{al}^{\mathbf{1 0}}$ showed that endodontically treated teeth can be reinforced with the use of resin composite restoration. The flowable composite reinforces the tooth, helps in achieving higher bond strengths and minimizes the inclusion of air voids.

Although many techniques with various materials have been suggested, resin based restorative materials with toothcolored fiber post may be considered the best option because of several advantages such as a fiber post with fractured teeth, as it interlocks the two fragments, minimizes the stress on the reattachment tooth fragments.

\section{Conclusion:-}

Reattachment of a tooth fragment is a viable technique that restores function and aesthetics with a very conservative approach in single visit and can be considered when treating patients with coronal fractures of the anterior teeth, especially in younger patients. Even though there are an array of post design options available in this clinical situation success is dictated by remaining tooth structure after endodontic therapy.

\section{References:-}

1. Shivakumar A, Bardvalli SG (2011): An alternative approach for re-attachment of the fractured fragment -A case report. Int J Cont Dent. 3(2).

2. Sultana R, Howlader MR, Alam S, Moral AA and Akter K (2016): Reattachment of fractured anterior tooth fragment: An approach in endo esthetic view: J Bang Sheik Muj Med Univ.9;113-116.

3. Sapna CM, Priya R, Sreedevi NB, Rajan RR, Kumar R (2014): Reattachment of Fractured Tooth Fragment with Fiber Post: A Case Series with 1-Year Follow up. Hind Publi Corp. 3(11).

4. Agrawal A, Manwar NU, Chandak MG (2011): Reattachment of Anterior Teeth Fragments with Two Different Treatment Techniques: Report of Two Cases. Int J Dent Clin.3(1):107-108.

5. Vashisth P, Mittal M, Singh AP (2012). Immediate reattachment of fractured tooth segment: A biological approach. Ind J Dent Resear.

6. Yadav A, Shetty N (2013): Fractured tooth rebonding: A ultra-conservative approach. J Inter dis Dent.5:3(2); 129.

7. Macedo GV, Diaz PI, Fernandes CAD, Ritter AV (2008): Reattachment of Anterior Teeth Fragments: A Conservative Approach. J Esthet Restor Dent: 20;5-20.

8. Dean JA, Swartz ML, Avery DR (1986): Attachment of anterior tooth fragments. Amer Acad Pedia Dent. $8 ; 2: 139$.

9. Londhe CSM, Garge BHG, Sudeep MS (2008): Reattachment of Crown Fragment for Immediate Esthetics. MJAFI. 64; 387-388.

10. Trope M, Mojirade AD, Funmilayo ASIM, Olaide GS (2011): Reattachment of anterior fragment tooth: A 2Year Review of a Case. Int J Prost Rest Dent; 1(2):123-127.

11. Martos J, Koller CD, Silveria LFM, Neto JBC (2012): Crown fragment reattachment in anterior-fractured tooth. Eur J Gen Dent. 1;(2):112-115.

12. Jyothi M, Jyothirmayi BSL, Mounika A, Girish K, Keerthi MHS (2016): Reattachment Conservative management of complicated crown fractures in anterior teeth. 2(1):10-13. 